2019-07

\title{
Achieving energy resilience through smart storage of solar electricity at dwelling and community level
}

\section{Gupta, R}

http://hdl.handle.net/10026.1/15124

10.1016/j.enbuild.2019.04.012

Energy and Buildings

Elsevier BV

All content in PEARL is protected by copyright law. Author manuscripts are made available in accordance with publisher policies. Please cite only the published version using the details provided on the item record or document. In the absence of an open licence (e.g. Creative Commons), permissions for further reuse of content should be sought from the publisher or author. 


\title{
Achieving energy resilience through smart storage of solar electricity at dwelling and community level
}

\author{
Rajat Gupta*, Adorkor Bruce-Konuah, Alastair Howard \\ Low Carbon Building Research Group, Oxford Institute for Sustainable Development, School of Architecture, Oxford Brookes University, Oxford, United \\ Kingdom
}

\section{A R T I C L E I N F O}

\section{Article history:}

Received 30 September 2018

Revised 22 February 2019

Accepted 10 April 2019

Available online 14 April 2019

\section{Keywords:}

Energy resilience

Smart storage

Electricity consumption

Solar generation

Community

\begin{abstract}
A B S T R A C T
This paper empirically evaluates the extent of energy resilience achieved in a socially-deprived community in Oxford, through deployment of solar photovoltaic (PV) systems and smart batteries (internet enabled and controllable) across a cluster of 82 dwellings (households). The methodological approach comprised dwelling and household surveys, along with high frequency monitoring of household electricity consumption, solar PV generation, battery charge and discharge data. In the monitored households, average daily electricity consumption was found to be positively related with dwelling size, number of occupants and number of appliances used. Although 117 MWh of PV electricity was generated within a year across 74 dwellings, peak generation did not match peak consumption, demonstrating the need for battery storage. Home batteries were found to increase self-consumption of PV electricity and offset grid demand through discharge of stored PV electricity marginally at an average of $6 \%$, depending on the size of the PV system, surplus PV electricity available and size of the battery. Aggregating solar generation and storage at a community level showed that peak grid electricity demand between 17:00 and 19:00 was reduced by $8 \%$ through the use of smart batteries across 74 dwellings. In future, a local energy sharing scheme could be developed, wherein not all dwellings would need to have solar PV systems, but rather have internet enabled batteries that could be monitored and controlled virtually.
\end{abstract}

(C) 2019 Elsevier B.V. All rights reserved.

\section{Introduction}

Resilience is defined as the capacity to recover quickly from difficulties [1]. With the pressing need to transition to a low carbon economy, planning and preparing for energy resilience is becoming increasingly important in an energy system consisting of a significant proportion of decentralised renewable energy sources and a decarbonised power system [2]. Between 2014 and 2015, electricity generation from renewable sources increased by $29 \%$ and amongst all renewable sources, solar photovoltaic (PV) generation increased by $87 \%$ in 2015 [3]. On their own, renewable energy systems provide very little resilience - the intermittency in renewable energy generation means that peak generation may not always match peak consumption. At household level, this is often evident in the daily profiles showing electricity consumption and locally generated electricity (Fig. 1). Since the power output from the renewable sources cannot be controlled, storage plays a vital role in improving the overall stability and reliability of this power system.

\footnotetext{
* Corresponding author.

E-mail address: rgupta@brookes.ac.uk (R. Gupta).
}

According to the Government report on delivering UK energy investment, the challenges to electricity supply in the UK are the increasing risks of blackouts and the inability of ageing infrastructure to cope with changing generation and needs [2]. During the winter of 2013-14, about three million UK consumers experienced power disruptions as a result of severe weather causing damage to electricity infrastructure. Although over $95 \%$ of the disrupted customers had supplies restored within $24 \mathrm{~h}$, the impact of such disruptions can be distressing particularly to the current modern way of life.

Energy storage capabilities have been identified as one of the physical means to achieving resilience [5]. Storage refers to the processes and technologies which have the capacity to capture energy and release it for consumption at a later time. There is a wide range of storage technologies varying in capacity and speed and duration of response. Storage offers energy resilience as it is able to balance energy demand and supply and respond to sudden changes in conventional energy supply, i.e. stored energy can be discharged quickly in the events where there are disruptions in conventional supply. Storage also provides resilience in its ability to divert generated renewable energy from the existing, aging energy infrastructure, i.e. reduce export of generated renewable energy. 


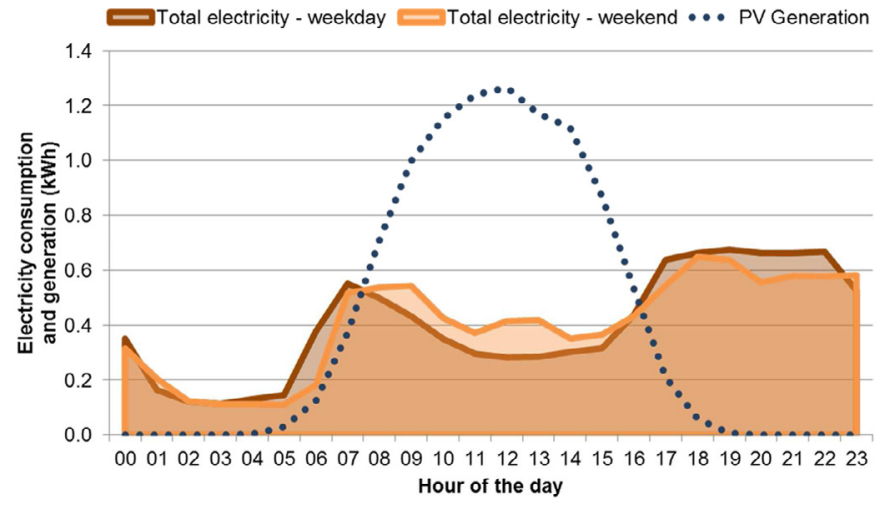

Fig. 1. Electricity consumption and PV generation profiles in a UK household: household occupied in the evenings and weekends only by one family with dependent children with a daily average electricity consumption of $9 \mathrm{kWh}$ [4].

Domestic electricity storage offers a number of benefits to the householders. The quick response of storage technologies such as batteries used on a household level means that they can respond to disruptions in electricity supply such as brownouts (intentional or unintentional drops in supply voltage) and blackouts (total power outage). Where distributed energy sources are available, storage offers an increase in self-consumption of the generated power which means demand from the grid is also reduced, i.e. power is supplied to the households while offsetting grid consumption. Brownouts are sometimes imposed in an effort to reduce the load on the grid and prevent total blackouts, hence measures to reduce grid load demand has far-reaching benefits. For the householders, electricity storage has the potential to reduce their household energy bills given that home batteries have smaller storage capacity and very low discharge time (milliseconds). In instances where there is dynamic pricing of electricity throughout the day, cheaper electricity can be stored and discharged during periods of more expensive power. In households with distributed renewable energy sources such as solar PV systems, excess PV generated electricity (when generation is greater than consumption) can be stored and discharged during periods of low or no generation (when consumption is greater than generation).

Given this growing significance of home batteries in the energy system, this study uses physical monitoring and household surveys to empirically demonstrate how distributed storage through home batteries can bring energy resilience in a real community by reducing average peak grid load and increasing self-consumption of local PV electricity. The batteries are linked to solar PV in each house and also have internet connections allowing them to be virtually coupled, so as to ensure that the maximum amount of solar generated electricity is used within the community. The study has been undertaken as part of a UK Government funded community energy research project called ERIC (Energy Resources for Integrated Communities).

\section{Domestic electricity storage: evidence to date}

In order for renewable energy sources to become a viable option on a large scale, they need to overcome the challenge of providing a steady supply of electricity to meet the constantly varying demand. Wind and solar sources vary unpredictably, and therefore energy storage solutions are a necessity. Pumped hydroelectric storage works on a large scale, where the terrain allows. However, battery technology is also developing, both large scale [6] and small (domestic and community) scale.

The uptake of energy storage systems is increasing in several countries. In 2016, Australia announced the introduction of a support package to encourage the uptake of solar storage in both domestic and commercial sectors as part of plans to shift the country to $90 \%$ renewables by 2030 [7]. In the UK, storage and flexibility has been identified as one of the better and smarter ways to power the nation with substantial cost savings $[8,9]$. In a response to the closure of existing power stations and the resulting challenges, the chair of The National Infrastructure Commission said that the UK has the opportunity to benefit from the innovations including storage and demand flexibility [10]. Policy Exchange, a leading think tank in the UK are also advocating for lower carbon taxes in battery, where surplus electricity generated is saved and released at a later time [11]. In addition, smart grid technology is developing, where as well as adjusting the supply of electricity, the demand could be tweaked to smooth off the peaks. So when demand hits a peak, the grid would be able to briefly cut power to household devices such as refrigerators - brief enough that nobody would notice but long enough to smooth out variations in the load [6].

Table 1 presents an overview of research studies on solar electricity generation and battery storage at dwelling and community levels. Most of the studies have tended to use modelling and algorithms to investigate the potential for net energy reduction, peak demand reduction and demand profile balancing, in addition to economic analysis that include different energy tariffs and subsidies. The studies outlined in the table could be divided into those that consider domestic PV/battery/grid relationships at an individual dwelling level [12-21], and those that expand this to multiple dwellings where generated and stored electricity is distributed over a microgrid [22-27].

Each study considers different scenarios, using different energy tariffs and incentives for prosumers, as well as different solar PV profiles and battery sizing. The general consensus is that combining solar PV generation with battery storage gives the homeowner increased benefits in terms of self-consumption, but that the size of these benefits will depend on the algorithms used to control battery charging and discharging [12], the sizing of the PV array and battery [20], the occupancy and demand profiles [26] and the tariffs and subsidies available $[13,18,19]$. The economic case for solar PV/battery installations at a domestic level is less clear. For example, Barbour and González [13] concluded that PV was more profitable than PV/battery systems under contemporary tariffs, while Bertsch et al. [19] found that technology costs and subsidies offered made PV/battery systems profitable in German scenarios but unprofitable in Irish scenarios and Para [27] concluded that solar thermal was still the only economically viable domestic renewable energy solution. Fares and Weber [14] went as far as saying that, although batteries could reduce grid demand by almost a third, the combination of storage inefficiencies and manufacturing could lead to a net increase in $\mathrm{CO}_{2}, \mathrm{SO}_{2}$ and $\mathrm{NO}_{\mathrm{x}}$ emissions.

On the other hand, models by Hemmati et al. [16], Pena-Bello et al. [18], Korkas et al. [22], Zepter et al. [24] and Parra et al. [26] all predicted significant reductions in electricity bills by using a combination of PV generation, battery storage and optimal grid export at an individual or community level, from $28 \%$ savings by storing electricity off peak and exporting at peak [16], to $60 \%$ savings using a combination of peer-to-peer trading and battery storage [24] and up to 66\% savings using an optimised community storage system [26].

Although several of the studies outlined in Table 1 have taken real-world data (climate data, solar irradiation, PV generation, electricity demand profiles, financial data), these have been used in models and algorithms to simulate electricity use, storage, charge and discharge of batteries, imports from the grid, exports to the grid, microgrid scenarios and financial gains and losses. The research presented in this paper has the novelty of investigating the deployment of solar PV systems and smart batteries across a 
Table 1

Summary of selected, recent studies that investigate domestic solar PV and battery scenarios for individual dwellings and clusters of dwellings.

\begin{tabular}{|c|c|c|c|}
\hline Study (year) & Type and location & Focus & Results \\
\hline Yahyaoui et al. [12] & $\begin{array}{l}\text { Model based on one case study } \\
\text { dwelling in Tunisia. }\end{array}$ & $\begin{array}{l}\text { Individual PV/battery algorithms } \\
\text { for efficiency. }\end{array}$ & $\begin{array}{l}\text { Fuzzy-logic algorithm provided system } \\
\text { autonomy and protected battery from } \\
\text { overcharging. }\end{array}$ \\
\hline Barbour and González [13] & $\begin{array}{l}\text { Model based on smart meter and } \\
\text { PV data from } 369 \text { dwellings } \\
\text { across USA. }\end{array}$ & $\begin{array}{l}\text { Individual PV/battery algorithms } \\
\text { with economic focus. }\end{array}$ & $\begin{array}{l}\text { Current price scenarios make PV more } \\
\text { profitable than PV/battery systems. }\end{array}$ \\
\hline Fares and Webber [14] & $\begin{array}{l}\text { Model based on homes in Texas, } \\
\text { USA }\end{array}$ & $\begin{array}{l}\text { Individual PV/battery analysis for } \\
\text { grid demand reduction and } \\
\text { associated toxic emissions. }\end{array}$ & $\begin{array}{l}\text { Typical battery system could reduce peak grid } \\
\text { demand by up to } 32 \% \text { but lead to increase in } \\
\text { overall energy demand and emissions of } \mathrm{CO}_{2} \text {, } \\
\mathrm{SO}_{2} \text { and } \mathrm{NO}_{\mathrm{x}} \text {. }\end{array}$ \\
\hline Nyholm et al. [15] & $\begin{array}{l}\text { Model based on PV generation and } \\
\text { energy consumption data from } \\
2000 \text { homes in Sweden. }\end{array}$ & $\begin{array}{l}\text { Optimising individual PV and } \\
\text { battery size to maximise } \\
\text { self-consumption. }\end{array}$ & $\begin{array}{l}\text { Batteries increase self-consumption by } 20-50 \% \text {, } \\
\text { and self-sufficiency by } 12.5-30 \% \text {. }\end{array}$ \\
\hline Hemmati et al. [16] & Model and algorithms & $\begin{array}{l}\text { Comparing individual PV/battery } \\
\text { storage, PV/battery export at } \\
\text { peak grid times and standalone } \\
\text { off-grid. }\end{array}$ & $\begin{array}{l}\text { PV/battery system reduced electricity bill by } \\
28 \% \text { by storing energy off peak and exporting } \\
\text { at peak. }\end{array}$ \\
\hline Weniger et al. [17] & $\begin{array}{l}\text { Model and algorithms using } \\
\text { German-based economics. }\end{array}$ & $\begin{array}{l}\text { Optimising individual PV and } \\
\text { battery size for optimal } \\
\text { economic gains. }\end{array}$ & $\begin{array}{l}\text { Long-term scenario suggests PV combined with } \\
\text { batteries will be the most economical } \\
\text { solution. }\end{array}$ \\
\hline Pena-Bello et al. [18] & $\begin{array}{l}\text { Model based on Swiss economic } \\
\text { data. }\end{array}$ & $\begin{array}{l}\text { An economic analysis to optimise } \\
\text { economics of PV } \\
\text { self-consumption and PV/battery } \\
\text { demand-load shifting. }\end{array}$ & $\begin{array}{l}\text { Best financial return per kWh when battery } \\
\text { used for PV self-consumption under a single, } \\
\text { flat tariff. }\end{array}$ \\
\hline Bertsch et al. [19] & $\begin{array}{l}\text { Model comparing German and Irish } \\
\text { scenarios. }\end{array}$ & $\begin{array}{l}\text { Analysing profitability of individual } \\
\text { PV/battery investments. }\end{array}$ & $\begin{array}{l}\text { PV/battery systems generally profitable in } \\
\text { Germany, but not yet in Ireland due to } \\
\text { technology costs and subsidy rates. }\end{array}$ \\
\hline Quoilin et al. [20] & $\begin{array}{l}\text { Models comparing scenarios in } \\
\text { various EU countries. }\end{array}$ & $\begin{array}{l}\text { Economic assessment of individual } \\
\text { PV/battery investments. }\end{array}$ & $\begin{array}{l}\text { Self-consumption is a non-linear function of PV } \\
\text { and battery sizes. } 100 \% \text { self-consumption is } \\
\text { not realistic without excessive oversizing of } \\
\text { PV and/or battery. Profitability will depend } \\
\text { mainly on subsidies for self-consumption. }\end{array}$ \\
\hline Luthander et al. [21] & $\begin{array}{l}\text { Meta study of self-consumption, } \\
\text { PV/battery and PV/demand-side } \\
\text { management. }\end{array}$ & $\begin{array}{l}\text { Overview of findings relating to } \\
\text { lowering peak demand and } \\
\text { increasing self-consumption. }\end{array}$ & $\begin{array}{l}\text { Relative self-consumption can increase by } \\
13-24 \% \text { with battery storage capacity of } \\
0.5-1 \mathrm{kWh} \text { per installed kW PV power, and } \\
2-15 \% \text { with demand-side management. }\end{array}$ \\
\hline Hill et al. [28] & $\begin{array}{l}\text { Overview of challenges of battery } \\
\text { storage and integration of PV and } \\
\text { grid systems. }\end{array}$ & $\begin{array}{l}\text { Technical study on modes of } \\
\text { operation for PV/battery/grid } \\
\text { systems. }\end{array}$ & $\begin{array}{l}\text { PV/battery coupling will increase reliability of } \\
\text { smart grid and enable more effective grid } \\
\text { management. }\end{array}$ \\
\hline Korkas et al. [22] & $\begin{array}{l}\text { Model and algorithms to provide } \\
\text { thermal comfort and reduced } \\
\text { energy in a 3-building microgrid. }\end{array}$ & $\begin{array}{l}\text { Algorithm to optimise energy use } \\
\text { and thermal comfort } \\
\text { incorporating a PV array, a wind } \\
\text { turbine and a battery. }\end{array}$ & $\begin{array}{l}\text { A 2-level closed-loop feedback strategy allows } \\
\text { efficient integration of renewables, reduced } \\
\text { energy costs and guaranteed thermal } \\
\text { comfort. }\end{array}$ \\
\hline Georgakarakos et al. [23] & Models and algorithms. & $\begin{array}{l}\text { Investigates feasibility of smart-grid } \\
\text { optimised buildings for } \\
\text { load-shifting and peak-shaving. }\end{array}$ & $\begin{array}{l}\text { Battery storage can change a building's } \\
\text { electricity profile, but regulation and } \\
\text { financial incentives are needed to make } \\
\text { smart-grid buildings feasible and } \\
\text { cost-effective. }\end{array}$ \\
\hline Zepter et al. [24] & $\begin{array}{l}\text { Model using test-case residential } \\
\text { buildings in London, UK. }\end{array}$ & $\begin{array}{l}\text { Models a smart electricity } \\
\text { exchange platform and the } \\
\text { interface between wholesale } \\
\text { electricity markets and prosumer } \\
\text { communities. }\end{array}$ & $\begin{array}{l}\text { Peer-to-peer trade and battery storage reduce } \\
\text { electricity bills by } 20-30 \% \text {. Combining P2P } \\
\text { and battery could reduce bills by almost } 60 \% \text {. }\end{array}$ \\
\hline Barbour et al. [25] & $\begin{array}{l}\text { Model and simulations using data } \\
\text { from Cambridge, MA (USA). }\end{array}$ & $\begin{array}{l}\text { Investigating PV/battery economics } \\
\text { for community storage/smart } \\
\text { grids. }\end{array}$ & $\begin{array}{l}\text { Optimum storage at the community level was } \\
65 \% \text { of that at the level of individual } \\
\text { households. Each kWh of community battery } \\
\text { was } 64-94 \% \text { more effective at reducing } \\
\text { exports from the community to the grid. }\end{array}$ \\
\hline Parra et al. [26] & $\begin{array}{l}\text { Model using data from a single } \\
\text { home to a 100-home community } \\
\text { in the UK. }\end{array}$ & $\begin{array}{l}\text { Investigates the optimum } \\
\text { community energy storage } \\
\text { systems in terms of round-trip } \\
\text { efficiency, annual discharge, costs } \\
\text { and rate of return. }\end{array}$ & $\begin{array}{l}\text { The community approach reduced costs by up } \\
\text { to } 66 \% \text {. Even the worst scenario for } \\
\text { community systems had better results than } \\
\text { the single home. }\end{array}$ \\
\hline Parra et al. [27] & Meta study review & $\begin{array}{l}\text { Investigates the potential for } \\
\text { community energy storage in the } \\
\text { wider energy system, and } \\
\text { challenges. }\end{array}$ & $\begin{array}{l}\text { Only thermal storage with water tanks is } \\
\text { currently economically viable. But future } \\
\text { projections suggest community energy } \\
\text { storage will smooth out demand profiles and } \\
\text { have economies of scale. }\end{array}$ \\
\hline
\end{tabular}


Table 2

Research methods.

\begin{tabular}{|c|c|c|c|}
\hline Method & & Purpose & Source of data \\
\hline 1. & Dwelling survey & Assess the physical conditions of the dwellings & Energy Performance Certificates (EPC) \\
\hline 2. & Household survey & Assess the household characteristics & Households \\
\hline 3. & $\begin{array}{l}\text { Baseline electricity } \\
\text { consumption }\end{array}$ & $\begin{array}{l}\text { Establish a benchmark for measuring the savings from the } \\
\text { installed systems }\end{array}$ & Meter readings and historic bills \\
\hline 4. & $\begin{array}{l}\text { Solar PV electricity } \\
\text { generation }\end{array}$ & $\begin{array}{l}\text { Assess the PV electricity generation, savings from use of PV } \\
\text { electricity and potential to increase self-consumption } \\
\text { through storage }\end{array}$ & $\begin{array}{l}\text { High frequency data from the technology } \\
\text { provider (30-min interval) }\end{array}$ \\
\hline 5. & Contribution of storage & $\begin{array}{l}\text { Assess the contribution of storage in increasing } \\
\text { self-consumption and reduction in average peak grid demand }\end{array}$ & $\begin{array}{l}\text { High frequency data from the technology } \\
\text { provider (5-min interval) }\end{array}$ \\
\hline
\end{tabular}

Table 3

Monitoring of baseline and post-installation electricity consumption, generation and storage analysis.

\begin{tabular}{lllll}
\hline Analysis & Elements & Time-period & Number of households & Source of data \\
\hline Baseline & Electricity consumption & Mar-15-Sep-15 (social-rented) & 48 & Historic bills and meter readings \\
& & Mar-16 (owner-occupied) & 8 & PV system provider \\
\multirow{3}{*}{ Post-installation } & PV electricity generation & Jun-15-May-16 & 54 & 74 \\
& Electricity consumption & Sep-16-Aug-17 & 76 & Battery dashboard (online) \\
& PV electricity generation & & 74 & 74 \\
& Contribution of storage & & 74 \\
& Reduction in peak grid demand & Sep-16-Aug-17 & \\
\hline
\end{tabular}

cluster of 82 dwellings and empirically evaluating the system over an extended period of time.

Statistics on household energy consumption in England show that approximately $14 \%$ of households are on a time of use electricity tariff (which offers cheaper electricity during off-peak demand periods such as night time) [29]. This low proportion makes a case for the need to couple energy storage systems with a form of renewable energy system. As the demonstration of the use and benefits of batteries on domestic level is currently in the pilot stages, rigorous evidence from real life studies is required to progress the investigation and understanding of the contribution of storage in increasing self-consumption of locally generated renewable energy.

\section{Research methods and case study dwellings}

A socio-technical methodology was adopted for the study to undertake field evaluation before (baseline) and after the installation of home batteries across 82 homes in Oxford (Table 2). Electricity consumption, generation and contribution of batteries were monitored using sensors, while household and dwelling surveys were conducted to understand the context to assess factors that have an impact on household electricity consumption. It is worth noting that the batteries were charged only by surplus PV electricity, and not from the mains grid. The study did not investigate changing occupants' behaviour to shift energy use profiles.

As shown in Table 3, dwelling electricity consumption, PV generation and contribution of storage were monitored by meter readings (pre-installation/baseline) and the batteries (post-installation). The varying sample sizes are due to accessibility and connectivity challenges due to which full data sets for all the 82 dwellings in which batteries were installed were not available. The analyses presented in the results section are therefore based on the data available.

The case-study community is located in Oxford, UK. The community is socially-deprived, not only in the south-east region of England but it was also within the $10 \%$ most deprived communities in England [30]. The community has 1200 households, over half of which were socially rented households (Local Authority and Housing Association). Over the previous eight years it has been the focus of a number of regeneration initiatives including solar PV installations and a new community centre which had a $60 \mathrm{kWh}$ solar
PV array and an electric vehicle charge point. About 82 dwellings comprising 82 households participated in the study, out of which 74 are social rented households and eight were owner-occupied (Table 3). Each dwelling had a solar PV system installed with system sizes ranging from $1.5 \mathrm{kWp}$ to $3.5 \mathrm{kWp}$ in the social housing dwellings (n:74), from $1.68 \mathrm{kWp}$ to $4 \mathrm{kWp}$ in the owner-occupied dwellings ( $\mathrm{n}: 8$ ). As part of the ERIC project, a $2 \mathrm{kWh}$ battery unit was installed in each dwelling between March 2015 and March 2016.

The fact that the majority of households in the study were social housing has an important implication: Many occupants were living on low incomes and were therefore low consumers of electricity. These "fuel poor" households therefore had different daily energy profiles than would be expected in more affluent households.

Table 4 presents the dwelling characteristics. Out of the 82 , about 70 were houses, four were bungalows and eight were flats.

The energy performance assessments of the dwellings were carried out between 2008 and 2015 (68\% in 2015). From the surveys conducted for the assessment, almost a third of the dwellings were found to have $100 \%$ low energy (LE) lighting and half of the dwellings had up to 50\% low energy lighting. The energy efficiency ratings of the dwellings were between $B$ and $E$. The average energy efficiency rating for the social-rented dwellings was $C$ and for the owner-occupied dwelling it was D. The potential energy efficiency rating that could be achieved in the social-rented dwellings was $\mathrm{B}$ and for the owner-occupied dwellings it was $\mathrm{C}$. Since the assessments were carried out before the installation, it was likely that the potential energy efficiency rating could be achieved with the installation of the solar PV systems and the battery units.

\section{Results}

\subsection{Baseline analysis}

The baseline electricity consumption was available for 54 dwellings (out of sample of 82 dwellings), measured from meter readings and using historic electricity bills where available. For the social housing dwellings, the baseline period was the period before the use of the solar PV systems and the batteries, while for the owner-occupied dwellings, it was the period before the use of the batteries since PV systems had been already installed in these 
Table 4

Characteristics of case study dwellings.

\begin{tabular}{|c|c|c|c|}
\hline Dwelling characteristics & & Social rented dwellings & Owner-occupied \\
\hline \multirow[t]{6}{*}{ Detachment type } & Mid-terrace & 31 & 1 \\
\hline & End-terrace & 26 & 4 \\
\hline & Semi-detached & 9 & 1 \\
\hline & Detached & & 2 \\
\hline & Ground-floor flat & 4 & \\
\hline & Top-floor flat & 4 & \\
\hline \multirow[t]{3}{*}{ Dwelling age } & Pre 1944 & 6 & 4 \\
\hline & 1945-1989 & 42 & 4 \\
\hline & Post 1990 & 26 & \\
\hline \multirow[t]{3}{*}{ Dwelling size } & Under $100 \mathrm{~m}^{2}$ & 67 & 3 \\
\hline & $101 m^{2}-149 m^{2}$ & 6 & 1 \\
\hline & Over $150 \mathrm{~m}^{2}$ & & 2 \\
\hline \multirow[t]{3}{*}{ Dwelling fabric (insulation) } & Full fill cavity wall & 43 & 5 \\
\hline & Partial & 28 & 1 \\
\hline & Timber frame (insulated) & 2 & \\
\hline \multirow{2}{*}{ Glazing type } & Full double-glazing & 74 & 7 \\
\hline & Partial double-glazing & & 1 \\
\hline Primary heating fuel & Gas central heating & 74 & 8 \\
\hline Secondary heating fuel & Electricity & 1 & \\
\hline Primary hot water heating fuel & Gas & 74 & 8 \\
\hline
\end{tabular}

Table 5

Descriptive statistics of baseline electricity consumption in the case study dwellings.

\begin{tabular}{llll}
\hline Daily electricity consumption $(\mathrm{kWh})$ & All & Social-rented & Owner-occupied \\
\hline Minimum & 2.9 & 2.9 & $5.2(3.4)$ \\
Maximum & 21.7 & 21.7 & $15.7(11.9)$ \\
Median & $7.2(7.1)$ & 7.1 & $8.8(5.5)$ \\
Average & $7.8(7.5)$ & 7.6 & $9.2(6.6)$
\end{tabular}

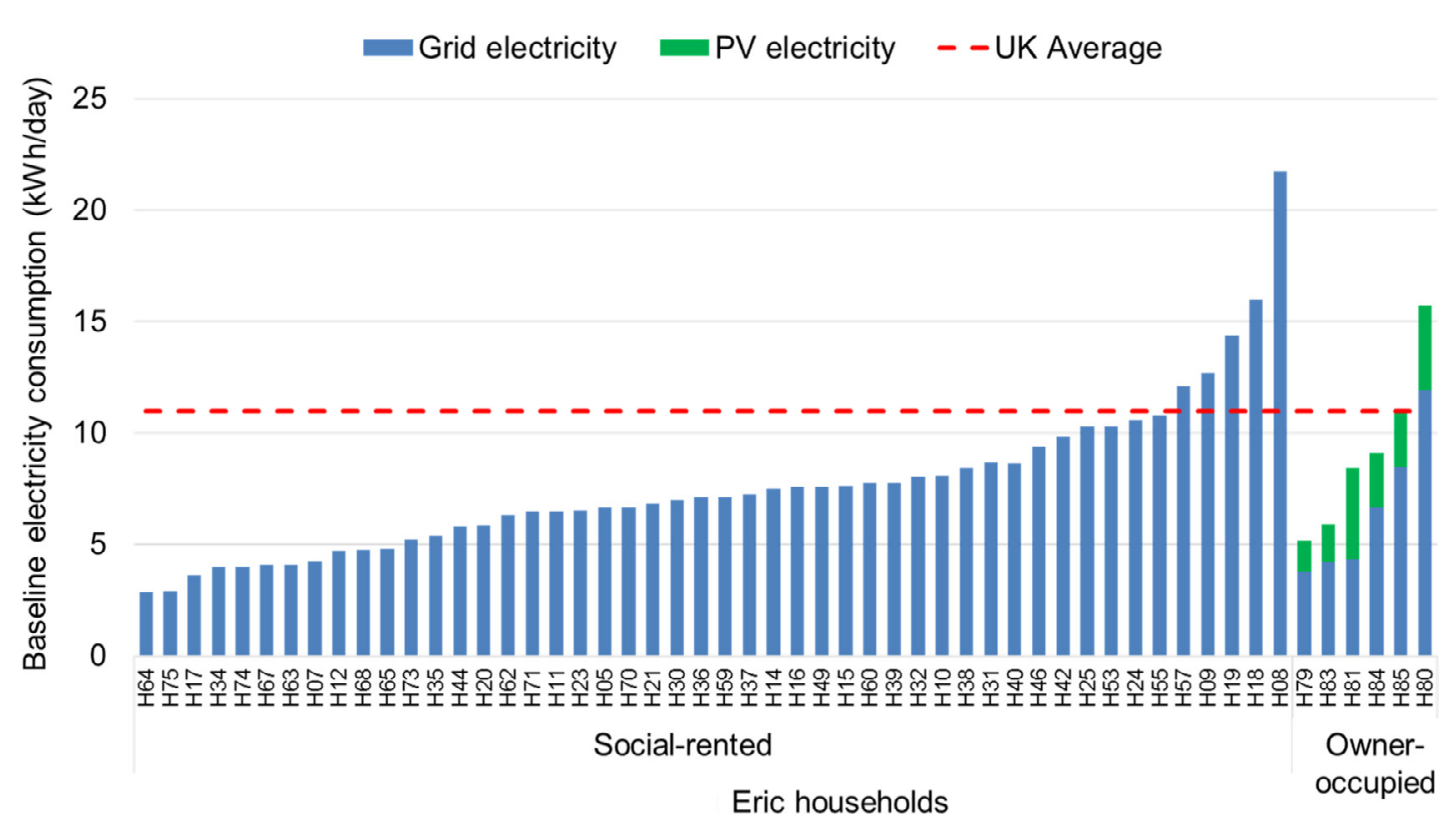

Fig. 2. Baseline average daily electricity consumption for 54 dwellings: by low social housing and owner-occupied dwellings.

dwellings. Table 5 presents the descriptive statistics on the consumption data, while Fig. 2 presents the average daily electricity use for each of the 54 dwellings, split into the social-rented households and the owner-occupied dwellings. The average daily electricity use for the 54 households was grouped into low, medium and high consumer ranges, based on the industry's standard values for annual domestic energy used by a typical consumer [31]. Typical Domestic Consumption Values (TDCVs) (i.e. median consumption) for electricity profile class 1 was used as this applies to all the ERIC households (i.e. domestic electricity credit meters or standard meters) during the baseline period. The 2015 TDV for low consumers is $2000 \mathrm{kWh} / \mathrm{year}$, for medium consumers it is
$3100 \mathrm{kWh} /$ year and for high consumers it is $4600 \mathrm{kWh} / \mathrm{year}$. Compared to the national average, the study dwellings were found to be low consumers and on average, the social-rented dwellings consumed less electricity than the owner-occupied households. Out of the 54 households presented, six were owner-occupied and already had solar PV systems installed use before the start of the study. Hence, their baseline electricity consumption comprised of grid electricity and PV generated electricity.

Analysis was carried out to assess how electricity use varies with different dwelling and household characteristics. Daily average electricity use for different dwelling and household groups was analysed to determine the significant variables, disaggregating 


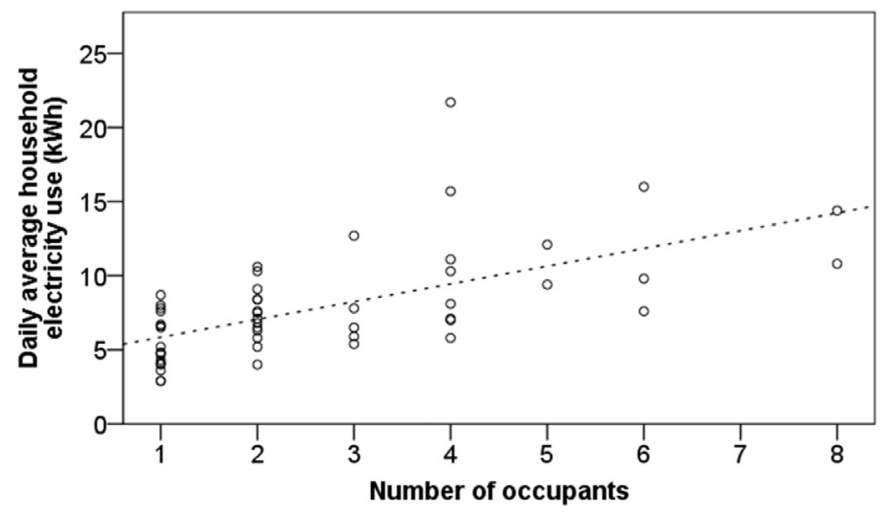

Fig. 3. Average daily electricity use and number of occupants in a household $(n=52)$.

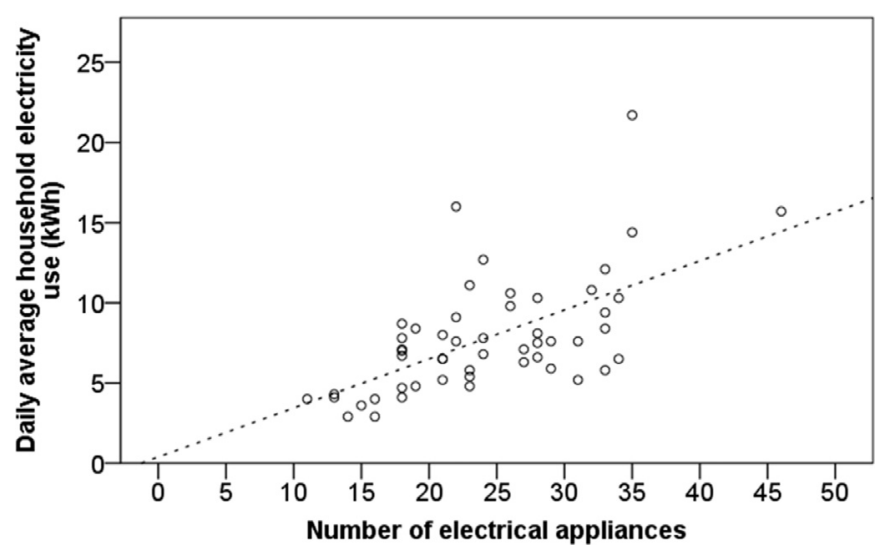

Fig. 4. Average daily electricity use and number of electrical appliances (excluding lighting) $(n=52)$.

for dwelling type and size, number of occupants, number of appliances and occupancy pattern. Linear regression analysis was used to cross-relate average daily electricity use to number of occupants (Fig. 3) and number of electrical appliances (Fig. 4). The number of households included in each analysis (and presented on the graph) is 52 . The number of occupants and the number of appliances were found to be significant $(p<0.05)$ with rising electricity use associated with increases in both. Both variables have strong correlations with household electricity use $(r=0.61)$.

Detailed analysis was undertaken to determine the amount of PV generated electricity ( $n: 74)$ which was consumed instantly (i.e. consumption during generation or self-consumption), and the excess PV electricity available in each dwelling, as shown in Fig. 5.
Out of the $117 \mathrm{MWh}$ of PV electricity generated in the year, $57 \mathrm{MWh}$ was consumed instantly, while the proportion of PV generated electricity consumed instantly ranged from $15 \%$ to $93 \%$ with an average of $51 \%$, so that an average of $31 \%$ of the annual household's electricity demand was met by PV system. This reinforced the need for having battery storage in these dwellings to increase the self-consumption of PV electricity.

Table 6 shows the dwelling electricity consumption, PV electricity generation and amount of PV electricity consumed instantly in the heating and non-heating seasons. The results presented in the table and the profiles are from households with different PV system sizes and different consumer types, i.e. low, medium and high consumers. Across all the households, there was little variation in the amount of PV generated electricity consumed instantly in the two seasons. In the heating season, a smaller amount of PV electricity was generated, and total household electricity consumption was higher with consumption peaks in the evening which significantly exceeded generation. Hence a smaller percentage of the household's total demand was met by PV generated electricity.

In the non-heating season, total consumption was lower and total generation was greater compared to the heating season. Because of the extended sunlight hours, the mismatch between peak consumption and PV generation was not as significant as in the heating season and hence the households were able to make more use of the electricity they were generating. In this season, PV electricity made up a greater proportion of the household's total demand. This was particularly highlighted in the low consumer household (H34). Amount of PV generated electricity consumed instantly was greatest in the high consumer household as their consumption exceeded generation (significantly in the heating season). An average of $79 \%$ of the PV electricity generated was consumed instantly and although they had a relatively big PV system size, because they were high consumers, PV electricity offset only an average of $31 \%$ of their total demand. In the medium consumer household presented, instant consumption of PV generated electricity was low and as can be seen from the profile, this was due to the time of use of electrical appliances (i.e. charging electric car at night, use of immersion water heater in the early morning and having a low demand during the day) resulting in a significant mismatch between consumption and generation. In the low consumer household, the seasonal impact on generation and the impact of the changes in electricity use profiles on self-consumption were highlighted. Although the difference in total consumption in the seasons was small, the consumption peaks were greater in the heating season compared to the non-heating season. In both $\mathrm{H} 34$ and H85, the mismatch between consumption and generation meant that only a small percentage of the generated electricity was consumed, resulting in large amounts of excess PV electricity available for storage.

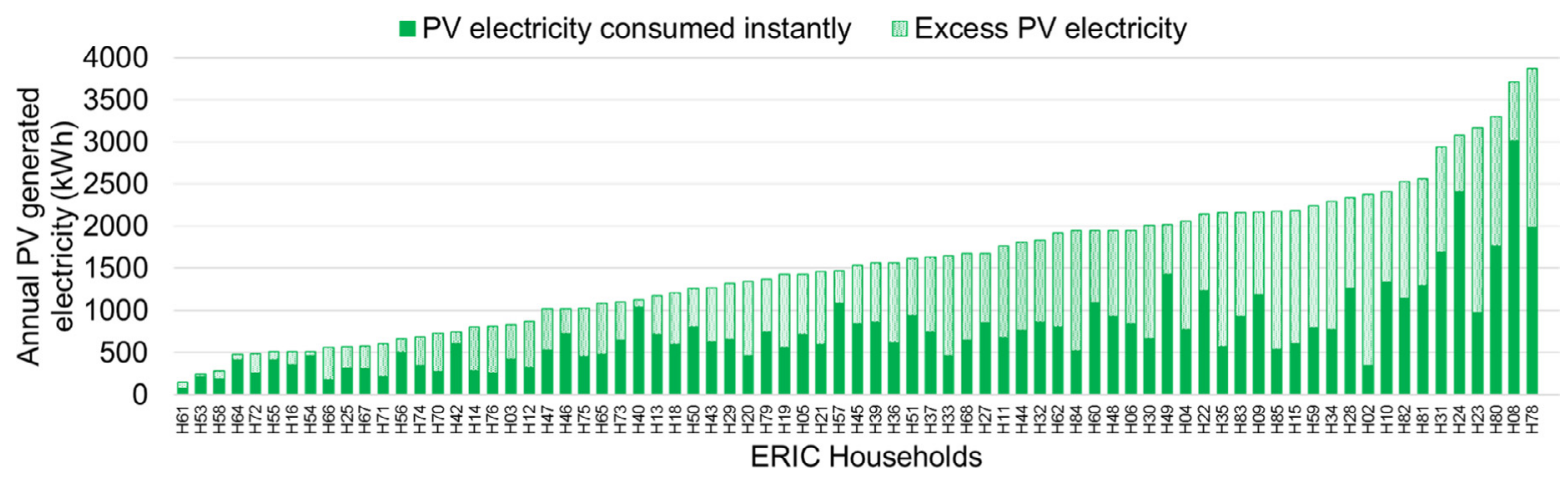

Fig. 5. Annual PV generated electricity consumed instantly and excess PV electricity (n:74). 
Table 6

Household electricity consumption, PV electricity generation and instant consumption of PV generated electricity.

\begin{tabular}{llll}
\hline Household & Daily average electricity & Heating season & Non-heating season \\
\cline { 2 - 3 } H34 & Total consumption (kWh) & 5.4 & 4.1 \\
PV & Total generation (kWh) & 4.9 & 8.3 \\
size: & PV electricity consumed instantly (percentage of total generation) & $1.9 \mathrm{kWh}(38 \%)$ & $2.5 \mathrm{kWh}(30 \%)$ \\
$2.25 \mathrm{kWp}$ & Percentage of household demand & $35 \%$ & $61 \%$ \\
H85 & Total consumption & 14.2 & 12.4 \\
PV & Total generation & 4.7 & 9.2 \\
size: & PV electricity consumed instantly (percentage of total generation) & $1.2 \mathrm{kWh}(25 \%)$ & $2.4 \mathrm{kWh}(26 \%)$ \\
$2 \mathrm{kWp}$ & Percentage of household demand & $8 \%$ & $20 \%$ \\
H24 & Total consumption & 25.6 & 22.7 \\
PV & Total generation & 6.5 & 12.5 \\
size: & PV electricity consumed instantly (percentage of total generation) & $5.6 \mathrm{kWh}(87 \%)$ & $8.9 \mathrm{kWh}(71 \%)$ \\
$3.25 \mathrm{kWp}$ & Percentage of household demand & $22 \%$ & $39 \%$ \\
\hline
\end{tabular}

Table 7

Comparison between grid electricity consumption in the baseline period and after the installation of the batteries.

\begin{tabular}{llll}
\hline Households & Daily average consumption & Baseline $(n=48)$ & Post-installation $(n=48)$ \\
\hline All & Minimum $(\mathrm{kWh})$ & 2.9 & 1.7 \\
households & Maximum $(\mathrm{kWh})$ & 21.7 & 20.2 \\
& Median $(\mathrm{kWh})$ & 7.1 & 5.4 \\
\multirow{4}{*}{ Social- } & Average $(\mathrm{kWh})$ & 7.7 & 7.3 \\
rented & Minimum $(\mathrm{kWh})$ & 2.9 & 1.7 \\
households & Maximum $(\mathrm{kWh})$ & 21.7 & 20.2 \\
& Median $(\mathrm{kWh})$ & 7.1 & 5.4 \\
Owner- & Average $(\mathrm{kWh})$ & 7.9 & 7.3 \\
occupied & Minimum $(\mathrm{kWh})$ & 3.8 & 3.3 \\
households & Maximum $(\mathrm{kWh})$ & 11.9 & 13.0 \\
& Median $(\mathrm{kWh})$ & 5.5 & 6.3 \\
& Average $(\mathrm{kWh})$ & 6.6 & 7.4 \\
\hline
\end{tabular}

Electricity consumption and generation profiles in Fig. 6 show the difference in instant consumption of PV electricity generated due to amount of electricity consumed. The magnitude of selfconsumption of PV electricity was dependent on the amount of electricity consumed and when it was consumed. For example, in H85, a significant proportion of electricity consumption occurred at night and very early in the morning. During the day, consumption was quite low and so only a small proportion of the PV electricity generated was consumed.

Since there was a wide variation in the size of solar PV systems installed in the case study dwellings, the impact of PV system size was assessed (Fig. 7). Total electricity consumed was plotted against percentage of PV generated electricity consumed instantly for four system sizes installed in the dwellings $(1.5 \mathrm{kWp}, 2 \mathrm{kWp}$, $2.25 \mathrm{kWp}$ and $2.5 \mathrm{kWp}$ ). In dwellings with $1.5 \mathrm{kWp}, 2.25 \mathrm{kWp}$ and $2.5 \mathrm{kWp}$ systems, as annual electricity consumption increased, the proportion of PV generated electricity consumed increased. The correlations ranged from weak to strong $(1.5 \mathrm{kWp}: r=0.61$, $2.25 \mathrm{kWp}: r=0.47,2.5 \mathrm{kWp}: r=0.31$ ). From the scatter plot, it can be seen that the majority of households were low to medium consumers (up to $3000 \mathrm{kWh}$ per year) with a range of PV sizes, where they consume up to $60 \%$ of the PV generated electricity.

From the above baseline analysis, it was evident that there was a need to increase self-consumption in the households and this could be achieved through increasing electricity consumption during the day (i.e. time shifting electricity demand), reducing the PV system size (i.e. to reduce excess PV generated electricity) or including storage to store and discharge PV electricity for use when generation exceeds consumption (e.g. in the mornings and evenings).

\subsection{Post-installation assessment}

The installed batteries, each having capacity of $2 \mathrm{kWh}$, were connected to the dwelling electricity meter, and the installed PV system and a control algorithm was used to determine the charge and discharge cycles of excess PV generated electricity. The batteries were connected via the internet to record and transmit high frequency data (30 second interval) about the dwelling's grid electricity import, PV electricity generation and consumption, PV electricity stored in the battery and battery electricity consumption. The high frequency data were accessed from an online dashboard, aggregated over $5 \mathrm{~min}$ and downloaded for analysis. The contribution of storage through the batteries was assessed from 1 September 2016 to 31 August 2017 (365 days). Due to connectivity issues (loss of internet connection), full set of data for 82 dwellings were not available. The model for charging and discharging was such that the battery charged when there was excess PV electricity generation and discharged when the household's demand exceeded generation. A minimum power rate of approximately $200 \mathrm{~W}$ was set for the batteries to allow for better battery charge/discharge cycle. The amount of PV electricity discharged from the battery was the percentage increase in self-consumption of PV generated electricity in the household.

Following the installation of the solar PV systems and the batteries, the dwelling electricity consumption comprised of three sources: grid electricity, PV electricity consumed instantly, and PV electricity stored in the battery. Table 7 presents the descriptive statistics of the daily electricity consumption in the baseline period and the period after installation of batteries for 48 dwellings, to assess if any energy savings were achieved. Interestingly, the average daily electricity consumption in the baseline period for the 48 households was found to be $7.7 \mathrm{kWh} /$ day against a daily average value of $7.3 \mathrm{kWh} /$ day for grid electricity consumption post installation of batteries. Across the socialrented households, average grid electricity consumption decreased by $0.5 \mathrm{kWh} /$ day. Across the owner-occupied households, there was an average of $0.8 \mathrm{kWh} /$ day increase in grid electricity consumption. Fig. 8 shows the distribution of daily average grid electricity consumption in the baseline and post-installation periods. As evident, 

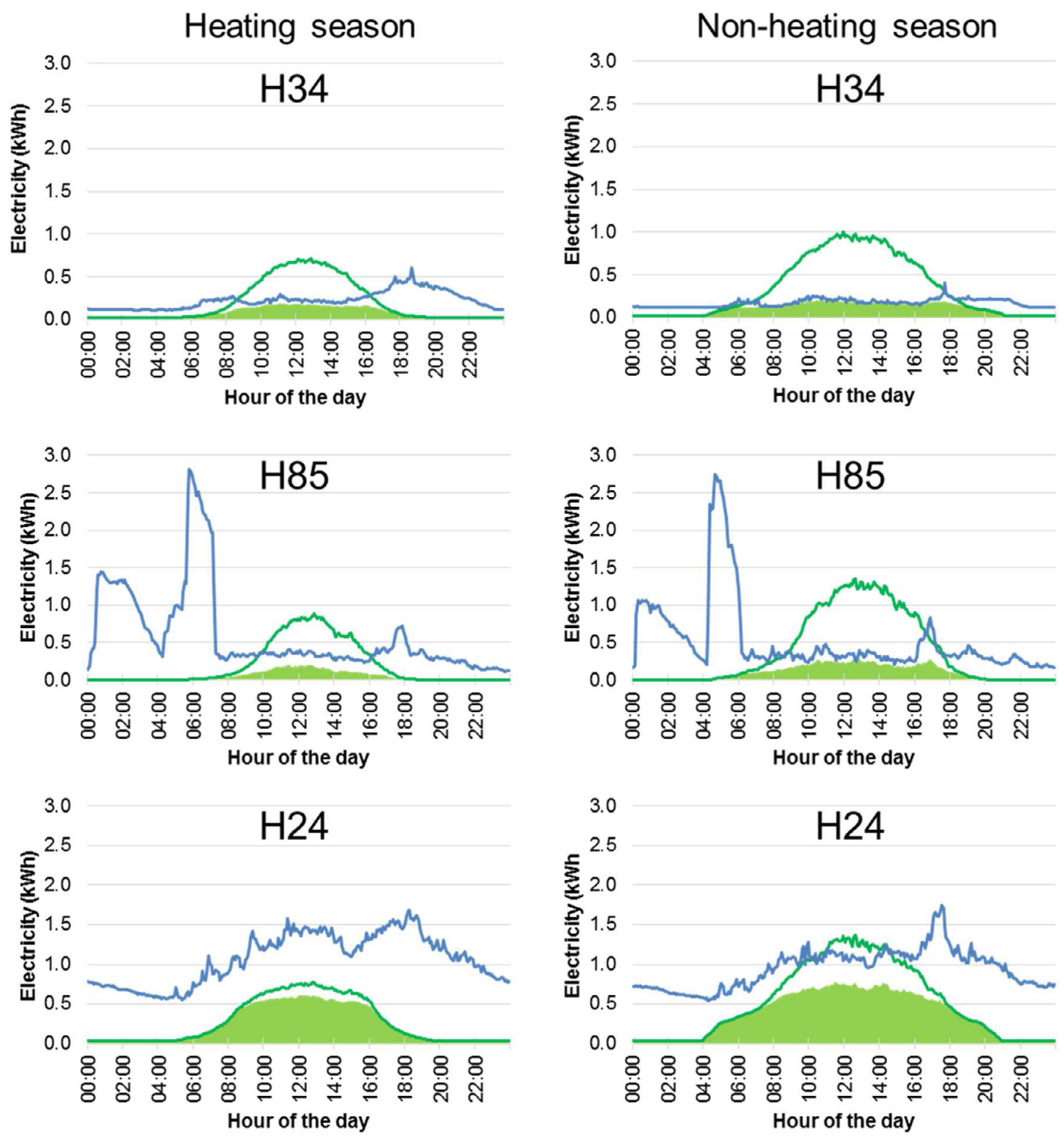

Consumption from PV

PV generation

Total consumption

Fig. 6. Instant consumption of PV generated electricity in case study households during the heating season (left) and non-heating season (right).

the histograms in both periods are skewed to the left confirming that the case study households were generally low electricity consumers.

As shown in the baseline results, excess PV generated electricity was available, even after instant (self) consumption in the case study dwellings. In the non-heating season, increase in selfconsumption by using store PV electricity (in the batteries) ranged between $0 \%$ and $29 \%$ with an average of $5.7 \%$ and in the heating season, it was between $0 \%$ and $19 \%$ with an average of $4.7 \%$. The absolute values of discharged solar PV electricity from the battery were quite low and did not rise above $1.4 \mathrm{kWh}$. This indicated that the maximum state of charge of the batteries was approximately $70 \%$. Even with a maximum of $1.4 \mathrm{kWh}$, the averages of the amount of PV electricity discharged from the batteries were low in both seasons. In the heating season, increase in self-consumption was greater than in the non-heating season.

To assess the impact of household consumer type (i.e. low, medium, high) on percentage increase in self-consumption through battery storage, three categories of percentage increase in selfconsumption were defined: low increase ( $\leq 1.9 \%$ ), medium increase $(2 \%-4.9 \%)$ and high increase $(\geq 5 \%)$. Table 8 presents the number of households that fell into these categories. In all the households where increase in self-consumption was below $1.9 \%$, two-thirds were low electricity consumers. The proportion of medium electricity consumer households was highest in the high increase in self-consumption category and this was double from the proportion in the medium increase in self-consumption category. The figures showed that the medium electricity consumer 


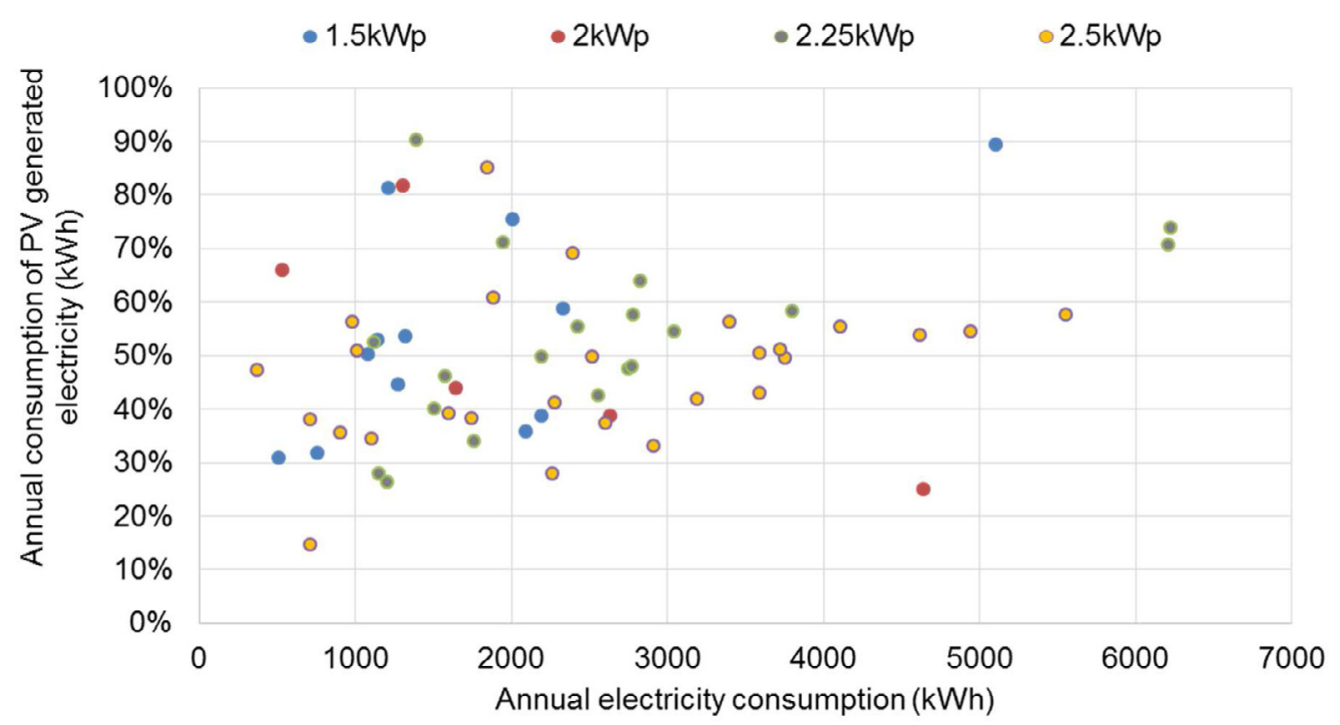

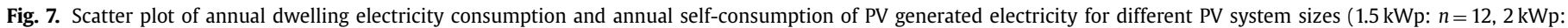
$n=5,2.25 \mathrm{kWp}: n=19,2.5 \mathrm{kWp}: n=27)$.

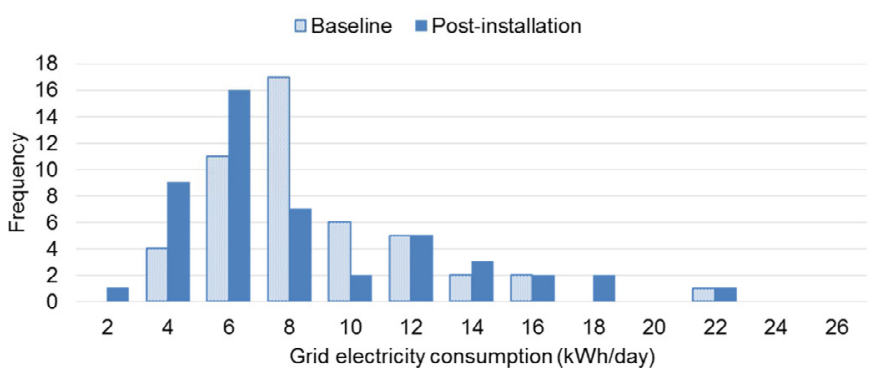

Fig. 8. Histogram of grid electricity consumption estimated in the baseline period $(n=4854)$ and measured in after the installation of the batteries $(n=4874)$.

households made the most use of the batteries. Within the medium electricity consumer households, 18 out of 25 increased their self-consumption of PV electricity by $5 \%$ or more. In the low and high electricity consumer households, increase in selfconsumption by $5 \%$ or more occurred in seven out of 22 and 15 out of 27 households respectively.

In the monitored year, the amount of PV electricity discharged from the batteries ranged from $4 \mathrm{kWh}$ to $317 \mathrm{kWh}$ with an average of $105 \mathrm{kWh}$ - about a total of $8 \mathrm{MWh}$ of PV generated electricity was discharged from the batteries. Fig. 9 shows the annual household electricity consumption split into grid electricity, PV electricity and battery electricity (i.e. PV electricity discharged from the battery). During the year, the proportion of battery electricity contribution ranged from $0.3 \%$ to $13 \%$ with an average of $3.4 \%$.

Figs. 10, 11 and 12 present daily profiles of electricity consumption and generation for low (Fig. 10), medium (Fig. 11) and high electricity (Fig. 12) consuming case study dwellings (households), showing instant consumption of PV generated electricity and discharge of stored PV generated electricity in the heating season (left column) and in the non-heating season (right column). In these figures, the area shaded blue is the electricity from the grid, the area shaded green is the electricity from the PV (instant consumption) and the area shaded orange of the electricity discharged from the battery (increase in self-consumption of PV electricity). The green continuous line is the PV electricity generation profile. Appendix 1 summarises the values for electricity consumption, generation and self-consumption of PV electricity (instant consumption and contribution of storage) in the case study dwellings (low, medium, high consuming households).

In Fig. 10, H35 has a $2.25 \mathrm{kWp}$ PV system installed which generated enough energy to meet the entire household demand in both seasons. However, it had a very low baseload which did not rise above $0.3 \mathrm{kWh}$ during the day (maximum of $0.28 \mathrm{kWh}$ in the heating season and $0.22 \mathrm{kWh}$ in the non-heating season occurring for less than one hour in the day), hence discharge from the battery was very minimal. The battery discharged an average of $0.1 \mathrm{kWh}$ per day which was only $5 \%$ of the battery capacity. In this household, initial self-consumption of PV electricity was $25.3 \%$ and it was increased by an average of $1.6 \%$ through storage. In $\mathrm{H} 15$, as the baseload increased to $0.5 \mathrm{kWh}$ in the evening, the discharge from the battery was significantly improved in the non-heating where almost half of the evening's demand was met by electricity from the battery (approximately $1 \mathrm{kWh}$ ). In the medium and high consumer households (Figs. 11 and 12), discharge from the batteries was also greater in the non-heating season. Discharge was usually in the evenings in an attempt to reduce peak grid demand. In all the households, there was still excess PV generated electricity after storage. Overall, increase in self-consumption is found to be greater in the medium consumer households and in households with a baseload exceeding the minimum power demand of the battery. In medium consumer households, there was a significant amount of

Table 8

Number of dwellings corresponding to different self-consumption categories.

\begin{tabular}{lllll}
\hline Increase in self-consumption categories & Total number of households & \multicolumn{3}{l}{ Household consumer type } \\
\cline { 3 - 5 } & & Low & Medium & High \\
\hline Low $(\leq 1.9 \%)$ & 11 & 7 & 2 & 2 \\
Medium $(2 \%-4.9 \%)$ & 23 & 8 & 5 & 10 \\
High $(\geq 5 \%)$ & 40 & 7 & 18 & 15 \\
\hline
\end{tabular}


- Grid electricity $\quad$ PV electricity $\quad$ Battery electricity

(n)

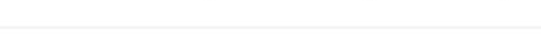

Fig. 9. Daily average household electricity consumption from the grid, PV and batteries.
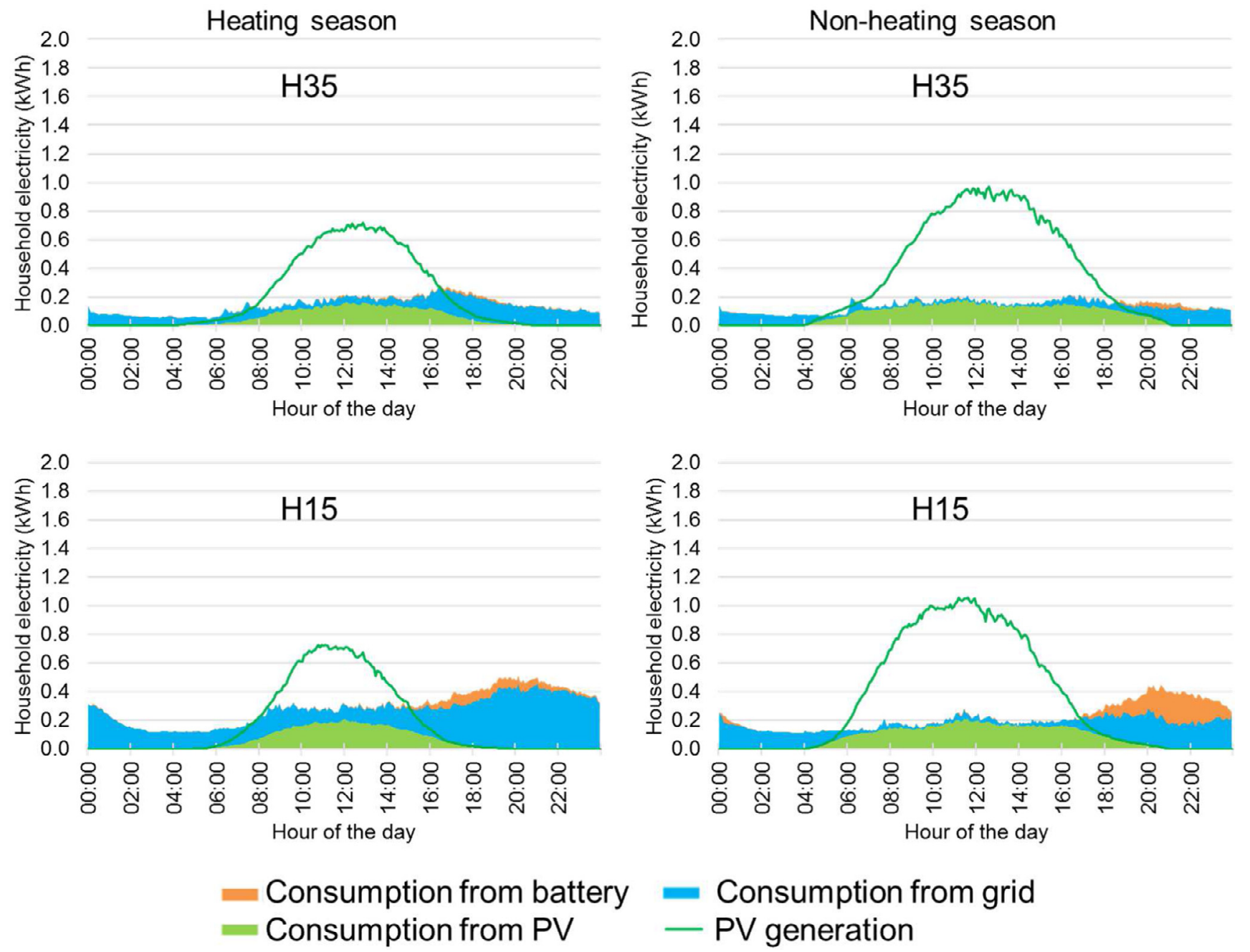

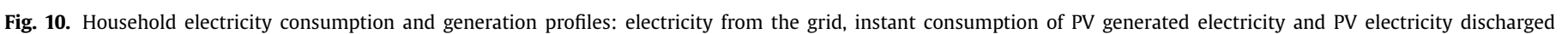
from the battery in the heating season (left) and non-heating season (right) in two low consuming households. 

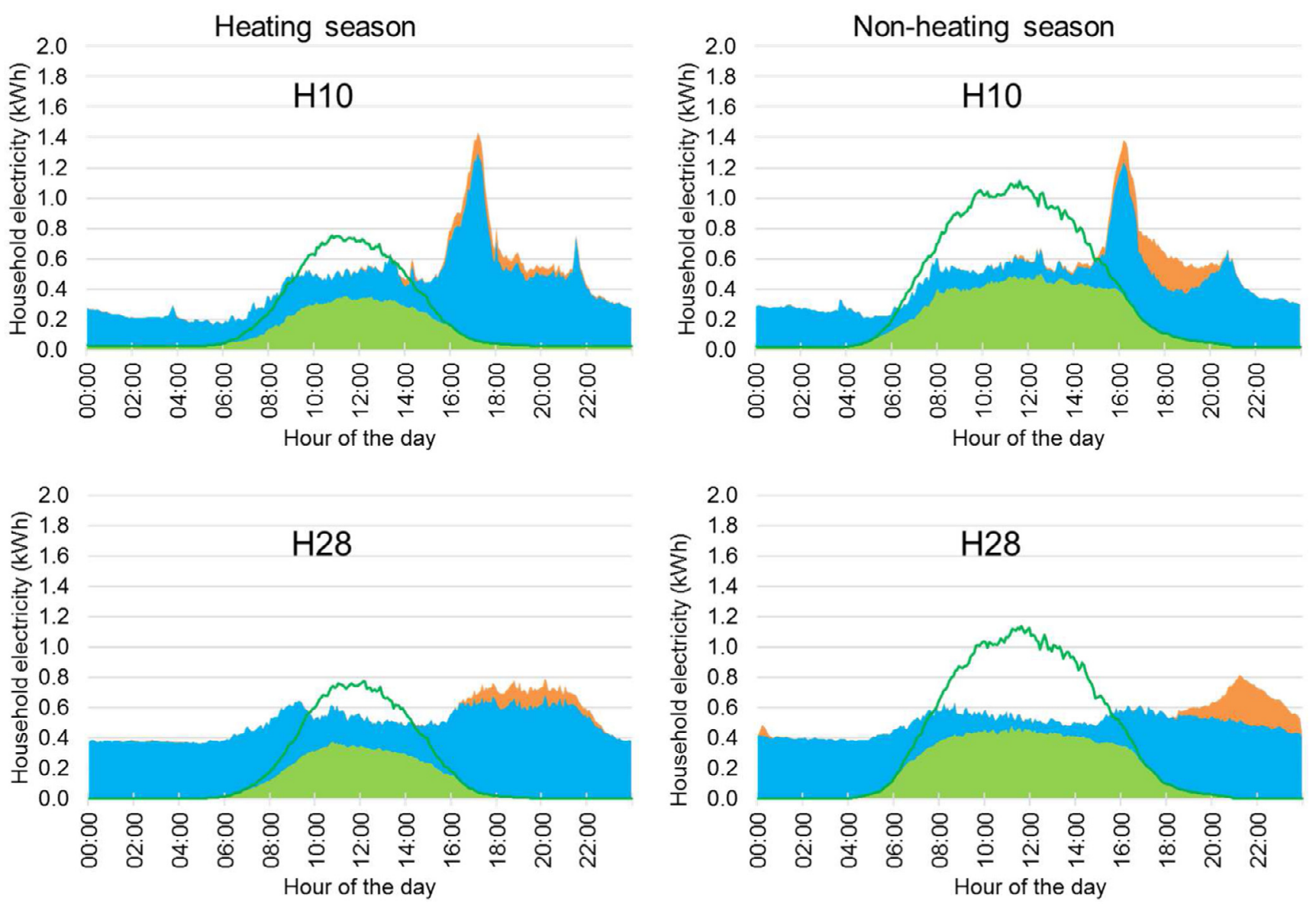

\section{- Consumption from battery - Consumption from PV}

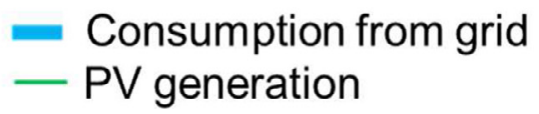

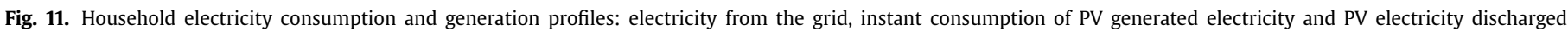
from the battery in the heating season (left) and non-heating season (right) in two medium consuming households.

excess PV generated electricity and a higher baseload that ensured that the batteries were discharged.

\subsection{Aggregating $P V$ generation and storage at a community level}

The demand for electricity across the case study dwellings was found to vary during the course of the day, with peaks at different times of the day determined by household activities. However when these were aggregated at the community level, the peaks smoothen out as illustrated in Fig. 13, which shows the aggregated electricity consumption of 74 case study dwellings. The peak electricity demand across the 74 households was found to be lower in the summer than in the winter. Across both seasons, there was surge in electricity consumption in the late afternoon. The surge was less evident in the summer as it was still light outside for longer and perhaps there was a preference for cold food and drinks (i.e. less use of kettles and cooking appliances). The peak demand for electricity, particularly in the heating season, is often a time of high stress for the national grid as the electric power system must balance generation with consumption. The typical peak grid demand time in the UK is between 17:00 and 19:00 [32-34] and in the case study community, peak grid demand times were found to be between 17:00 and 19:00 in the heating season but between 16:00 and 18:00 in the non-heating season (Fig. 13).

In addition to increasing self-consumption of PV generated electricity through domestic storage, discharge of the stored electricity (excess solar electricity) during the peak demand time, has the potential to reduce peak load on the national grid. This is why the impact of storage in the case study community on reducing peak grid electricity demand was evaluated by assessing the discharge of stored electricity during peak demand times. Figs. 14 and 15 show the profiles of electricity consumption from the grid and electricity discharged from the battery during the heating and nonheating seasons.

Using the identified peak times, it was found that peak grid electricity consumption was reduced by an average of $8 \%$ across the peak period in the heating season and $6 \%$ in the non-heating season. The profiles across both seasons show that discharge from the batteries occurred for an extended period of time outside of the peak times. This reduced the local community's demand for grid electricity. However, the benefit of reducing peak grid demand was minimised. Peak grid electricity demand, particularly in the heating season, is often critical for the national grid operators. Hence effective planning for dispatch of stored electricity would be crucial to ensure that it was matched with peak demand times. Using a peak period of 17:00 and 19:00 for both seasons, peak grid electricity demand was found to be reduced by $8.0 \%$ and $8.7 \%$ in the heating and non-heating seasons respectively.

Household interviews were also conducted (between June and August 2017) with a sample of 30 households (out of 82) to gain insight on householder's experiences with the battery and their perception of domestic storage. Overall the householders were 

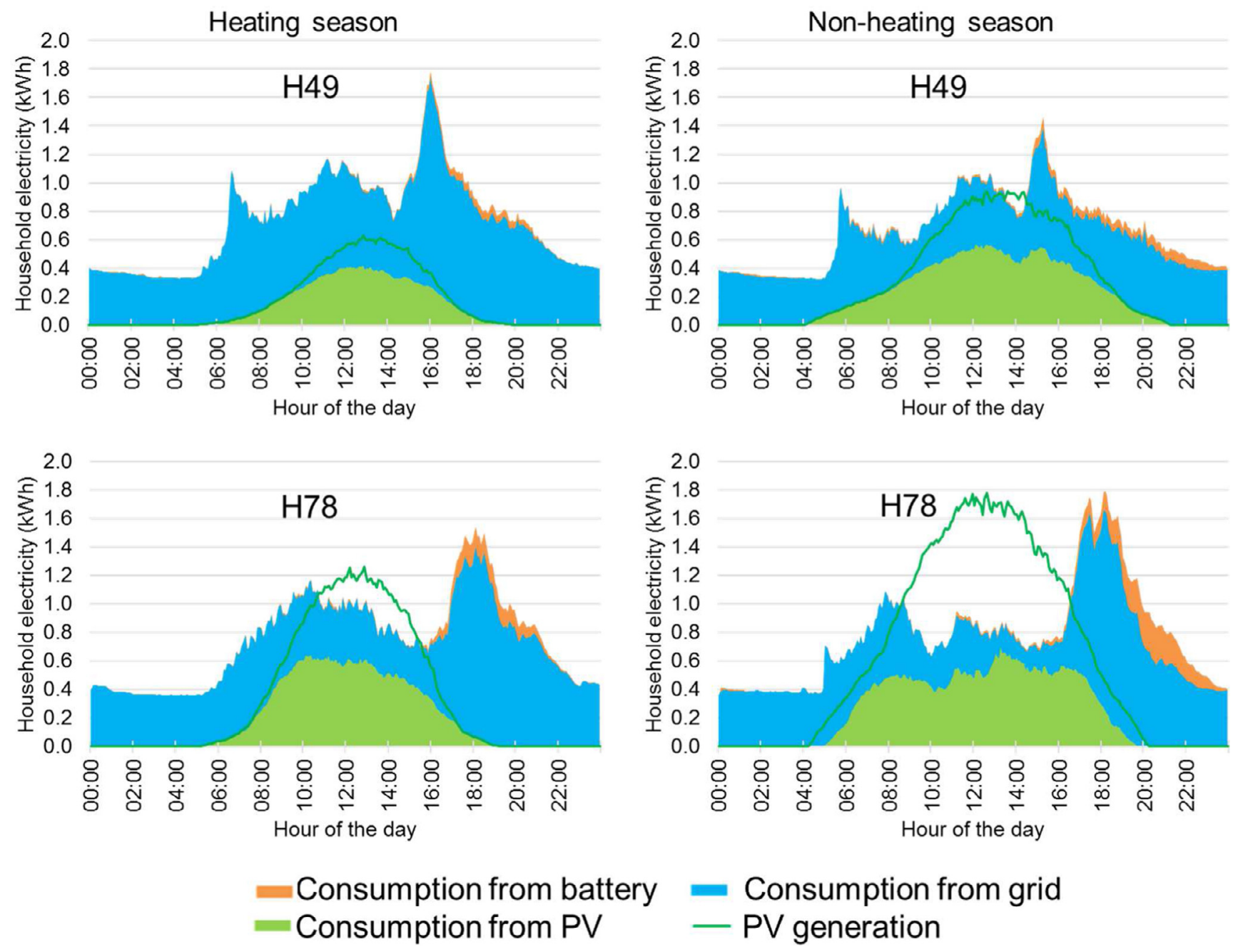

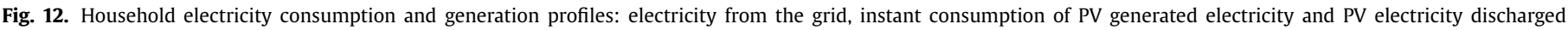
from the battery in the heating season (left) and non-heating season (right) in two high consuming households.

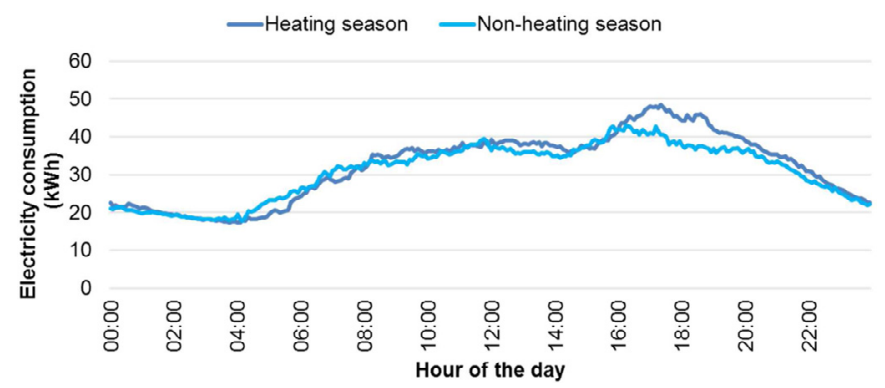

Fig. 13. Electricity consumption profiles in the heating and non-heating seasons at a community level ( $n=74$ dwellings).

satisfied with the installation of the battery. Although general opinion was that having a battery was beneficial, householders were not clear whether the battery offered additional electricity savings apart from savings received due to PV generation. Several households shared their poor understanding of the battery operation. Almost all of the householders felt that having a battery did not influence their daily habits of using home appliances. On a community share scheme where excess PV generated electricity from one household is shared with neighbours in the community who do not have solar PV systems (but have batteries), most of householders felt it was a good idea. If they had excess PV electricity after storage, they were happy to share that with others in the community.

\section{Discussion}

The systematic approach to monitoring and evaluation adopted in this study allowed detailed information to be collected on dwelling and household characteristics in order to conduct a rigorous assessment of the contribution of the smart batteries in dwellings with solar PV systems. Solar PV systems were found to generate a significant amount of electricity, offsetting the household's grid electricity demand and adding local renewable energy to the community. In the monitored year, $117 \mathrm{MWh}$ was generated from 74 dwellings and substantial surplus PV electricity available across the community which was not consumed due to the mismatch between peak electricity generation and peak consumption. The proportion of PV generated electricity consumed instantly was between $15 \%$ and $93 \%$ with an average of $51 \%$. The amount of surplus PV electricity was due to the household's electricity load and the size of their PV system. This significant amount of surplus PV generated electricity formed a strong case for integrating domestic storage systems (home batteries) with a renewable energy source (in this case, solar PV systems).

The contribution of home batteries in increasing the selfconsumption of PV generated electricity was between $0 \%$ and $29 \%$ with an average of $6 \%$ in a year. This increase in self-consumption 


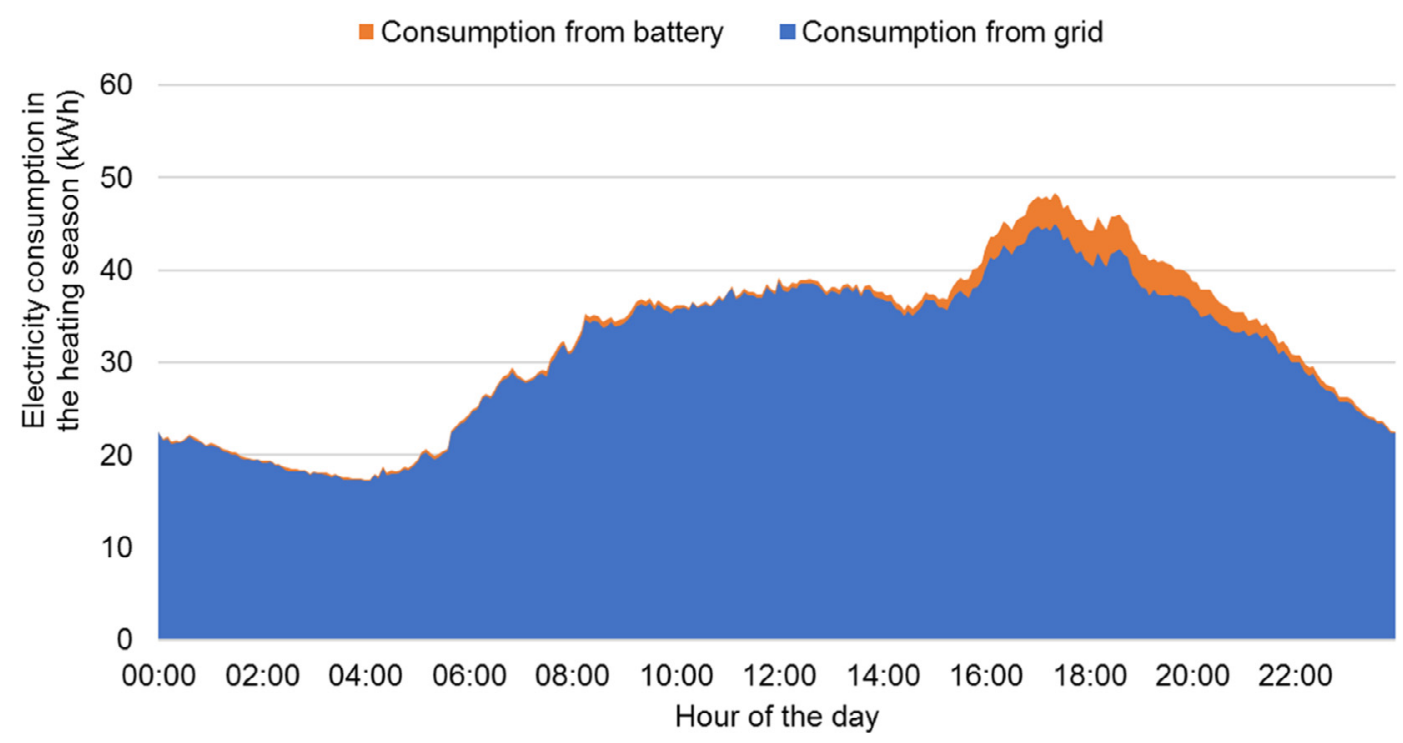

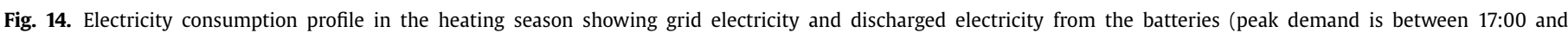
19:00).

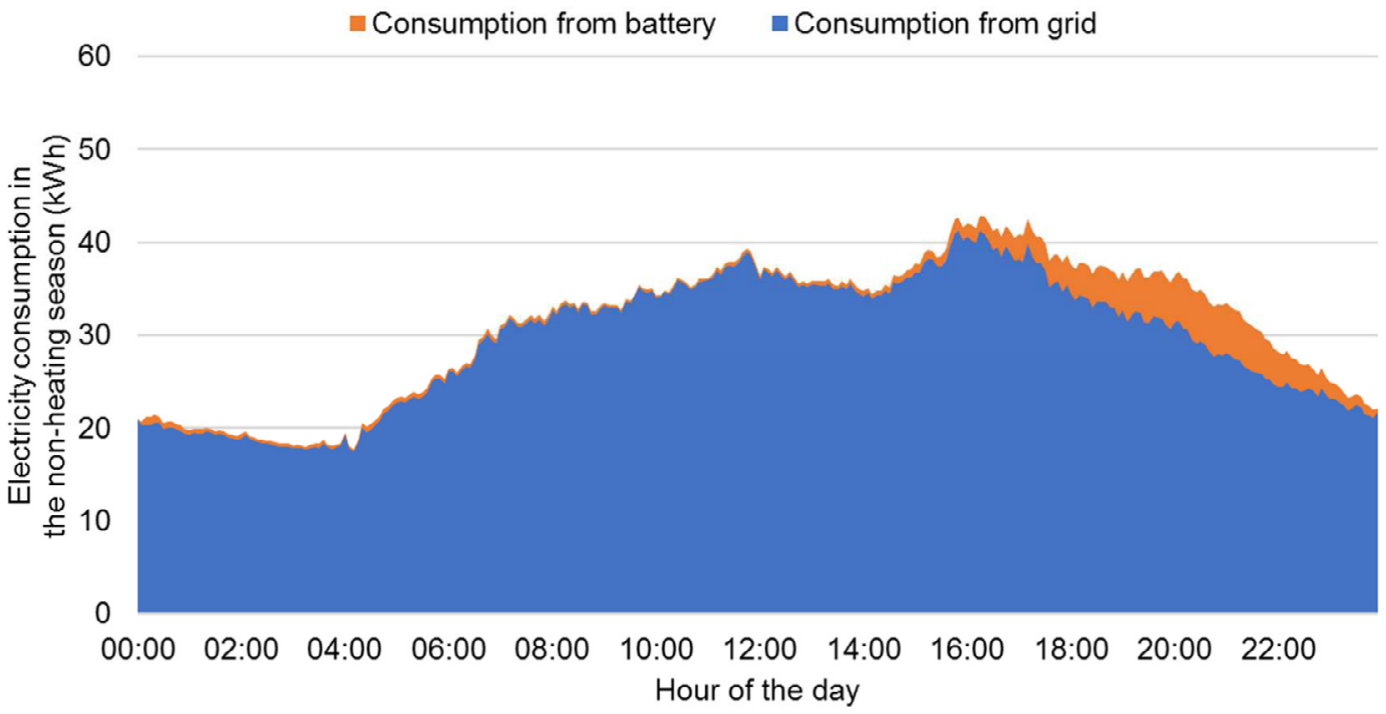

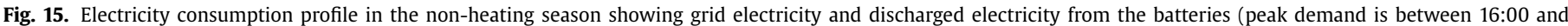
18:00).

was affected by the household's electricity load and the surplus PV electricity available. In some households, the surplus PV electricity was under-utilised due to the current battery size of $2 \mathrm{kWh}$ and the minimum baseload requirement of $200 \mathrm{~W}$. Hence there was still surplus PV generated electricity after storage. Discharge from the batteries contributed up to $11 \%$ of the household's electricity use, which resulted in an average annual saving of $£ 15.14$ (maximum of $£ 45.52$ ).

The results of the non-heating and heating seasons showed a (marginal) increase in self-consumption of PV electricity when adding a battery. In the non-heating season, a higher amount of PV electricity was generated and consumed instantly, hence a reduced amount was available for storage compared to the heating season. In the heating season, although a smaller amount of electricity was generated, a similar amount as in the non-heating season was consumed, indicating that batteries offer the potential to ensure that a maximum amount of the generated electricity is consumed in the heating season. Furthermore, household characteristics such as occupancy patterns also had an influence on self-consumption of locally generated electricity. From the household level analysis, it was shown that consumption during generation of PV electricity was lowest in the low consumer householders. As the case study households were generally lower consumers (compared to the national average), an aggregation across the community would ensure that a higher amount of the locally generated electricity was consumed within the community.

Aggregating the generation and storage across 74 dwellings, it was found that peak grid electricity demand between 17:00 and 19:00 was reduced by $8 \%$ through the use of the smart batteries. In future, to enhance the contribution of storage in reducing peak grid electricity demand, it is essential to understand deeply the household/community electricity use profile using smart meters, for planning and design of renewable energy systems.

\section{Conclusion}

This study has empirically evaluated the extent of energy resilience achieved through deployment of a large number of solar PV systems and smart batteries (internet enabled and controllable) across a cluster of dwellings (households) in Oxford. A wide 
variation in daily household electricity consumption was found, even across dwellings with similar built form and age band, and household characteristics (e.g. number of occupants, occupancy pattern, number of electrical appliances).

Findings from this study showed that solar PV systems generated a significant amount of electricity and in sunnier seasons, daily average PV electricity generated was close to household's daily average electricity demand. However, due to the mismatch between peak demand and peak generation, PV electricity only offset a low to moderate proportion of household electricity demand especially in dwellings that were occupied for some of the time compared to those occupied all the time. Storage was shown to increase self-consumption of PV electricity and further offset grid demand through discharge of stored excess PV electricity, although only marginally, again dependent on household type.

As self-consumption of PV generated electricity was influenced by factors such as type of consumer and occupancy pattern of the household, there is potential to further increase self-consumption of PV electricity and cost savings locally, through a local energy sharing scheme which would help to match local renewable energy supply with the local energy demand. A community energy sharing scheme could be developed, wherein not all households would need to have solar PV systems, but rather have internet enabled batteries that could be monitored and controlled virtually. These batteries could be charged when there was excess PV electricity available (after instantaneous self-consumption and charging of batteries in homes with solar PVs), and discharged when there was a demand for electricity in the community (by dwellings with/without solar PV).
In addition to maximizing the local use of renewable energy, domestic storage could also be aggregated and controlled to generate revenue (for the householders) through ancillary grid services market. Battery storage is particularly suited to deliver electricity at speed and this higher value energy reserve could also enable wider implementation of home batteries whose storage could be aggregated and controlled. The value of this energy is priced in the energy market, which is much higher than standard energy, since it reflects the importance of rapid response in order to prevent grid failure. It is evident that the combination of solar PV and home battery will be important in the drive towards smart energy systems in homes and communities.

\section{Acknowledgement}

This work was carried out as part of the research project Community controlled energy through virtual private energy networks entitled ERIC (Application number: 41744-306234), which was funded by Innovate UK's Localised energy systems competition. We are grateful to other members of the ERIC project, especially Moixa, Bioregional and Oxford City Council. Thanks are also due to the householders of the case study community for all their time and cooperation.

Appendix 1. Household electricity consumption, PV electricity generation, instant consumption of PV electricity and increase in self-consumption through storage, across case study low, medium and high electricity consuming households

\begin{tabular}{|c|c|c|c|}
\hline Dwelling (household) & Daily average electricity & Heating season & Non-heating season \\
\hline \multicolumn{4}{|c|}{ Low electricity consuming households } \\
\hline \multirow[t]{6}{*}{ H35PV size: $2.25 \mathrm{kWp}$} & Total consumption (kWh) & 3.4 & 3.3 \\
\hline & Total generation $(\mathrm{kWh})$ & 5.0 & 8.0 \\
\hline & PV electricity consumed instantly & 1.3 & 2.0 \\
\hline & Percentage of PV electricity consumed instantly & $26 \%$ & $24.6 \%$ \\
\hline & PV electricity discharged from the battery & 0.1 & 0.1 \\
\hline & Percentage increase in self-consumption & $1.9 \%$ & $1.4 \%$ \\
\hline \multirow[t]{6}{*}{ H15PV size: $2.5 \mathrm{kWp}$} & Total consumption & 7.0 & 5.3 \\
\hline & Total generation & 4.4 & 8.4 \\
\hline & PV electricity consumed instantly & 1.4 & 2.0 \\
\hline & Percentage of PV electricity consumed instantly & $32.5 \%$ & $24.4 \%$ \\
\hline & PV electricity discharged from the battery & 0.4 & 1.0 \\
\hline & Percentage increase in self-consumption & $10.1 \%$ & $11.4 \%$ \\
\hline \multicolumn{4}{|c|}{ Medium electricity consuming households } \\
\hline \multirow[t]{6}{*}{ H10PV size: $2.5 \mathrm{kWp}$} & Total consumption (kWh) & 10.8 & 11.8 \\
\hline & Total generation $(\mathrm{kWh})$ & 5.0 & 8.9 \\
\hline & PV electricity consumed instantly & 2.8 & 4.8 \\
\hline & Percentage of PV electricity consumed instantly & $56.6 \%$ & $54.4 \%$ \\
\hline & PV electricity discharged from the battery & 0.5 & 0.8 \\
\hline & Percentage increase in self-consumption & $10.0 \%$ & $9.6 \%$ \\
\hline \multirow[t]{6}{*}{ H28PV size: $2.5 \mathrm{kWp}$} & Total consumption & 12.6 & 12.8 \\
\hline & Total generation & 4.7 & 8.8 \\
\hline & PV electricity consumed instantly & 2.6 & 4.6 \\
\hline & Percentage of PV electricity consumed instantly & $55.6 \%$ & $52.5 \%$ \\
\hline & PV electricity discharged from the battery & 0.5 & 0.9 \\
\hline & Percentage increase in self-consumption & $11.4 \%$ & $10.2 \%$ \\
\hline \multicolumn{4}{|c|}{ High electricity consuming households } \\
\hline \multirow[t]{6}{*}{ H49PV size: $2.25 \mathrm{kWp}$} & Total consumption (kWh) & 17.8 & 16.1 \\
\hline & Total generation $(\mathrm{kWh})$ & 3.9 & 7.8 \\
\hline & PV electricity consumed instantly & 2.9 & 5.3 \\
\hline & Percentage of PV electricity consumed instantly & $74.5 \%$ & $68.0 \%$ \\
\hline & PV electricity discharged from the battery & 0.3 & 0.7 \\
\hline & Percentage increase in self-consumption & $8.6 \%$ & $8.5 \%$ \\
\hline \multirow[t]{6}{*}{ H78PV size: $4 \mathrm{kWp}$} & Total consumption & 18.0 & 18.7 \\
\hline & Total generation & 8.2 & 15.3 \\
\hline & PV electricity consumed instantly & 4.8 & 6.2 \\
\hline & Percentage of PV electricity consumed instantly & $58.5 \%$ & $40.3 \%$ \\
\hline & PV electricity discharged from the battery & 0.7 & 1.3 \\
\hline & Percentage increase in self-consumption & $8.0 \%$ & $8.2 \%$ \\
\hline
\end{tabular}




\section{References}

[1] Oxford Dictionaries. "Resilience". Available at: https://en.oxforddictionaries. com/definition/resilience (Accessed 20 January 2019).

[2] Department of Energy and Climate Change (2018). Energy consumption in the UK (2018). Available at: https://www.gov.uk/government/statistics/ energy-consumption-in-the-uk (Accessed 20 January 2019).

[3] Department for Business, Energy and Industrial Strategy (2016). Digest of United Kingdom Energy Statistics 2016, pp 155-195. Available at: https://assets.publishing.service.gov.uk/government/uploads/system/uploads/ attachment_data/file/577712/DUKES_2016_FINAL.pdf (Accessed 20 January 2019).

[4] Rajat Gupta, Nick Eyre, Sarah Darby, Karen Lucas, Laura Barnfield, Jo Hamilton, Ruth Mayne, Matt Gregg, Chiara Fratter, Bob Irving, in: Evaluating the Impacts of Low Carbon Communities (EVALOC) Final Report, Oxford Brookes University and University of Oxford, Oxford, UK, 2015, p. 52.

[5] Paul E. Roege, Zachary A. Collier, James Mancillas, John A. McDonagh, Igor Linkov, Metrics for energy resilience, Energy Policy 72 (2014) 249-256.

[6] David Lindley, Smart grids: the energy storage problem, Nature News 463 (7277) (2010) 18-20.

[7] Gareth Hutchens, Greens' want 1.2 households to install renewable energy storage, The Guardian (May 4) (2016). Available at: http://www.theguardian. com/environment/2016/may/05/greens-want-12m-households-to-installrenewable-energy-storage.

[8] Richard Anderson, Energy storage: the key to a smarter power grid, BBC News (2014). 24th AprilAvailable at: http://www.bbc.co.uk/news/business-27071303.

[9] A. Lever, D. Sanders, N. Lehmann, M. Ravishankar, M. Ashcroft, G. Strbac, M. Aunedi, F. Teng, D. Pudijanto, Can storage help reduce the cost of a future UK electricity system, Carbon Trust, Imper. College London (2016) 1-121.

[10] Press Association, Improved energy storage could help save Britain £8bn a year, says report, The Guardian (2016). 4th MarchAvailable at:http://www. theguardian.com/environment/2016/mar/04/improved-energy-storage-couldhelp-save-britain-8bn-a-year-says-report.

[11] R. Howard, Z. Bengherbi, Power 2.0: building a smarter, greener, cheaper electricity system, Policy Exchange, White paper (2016).

[12] Imene Yahyaoui, Souhir Sallem, M.B.A. Kamoun, Fernando Tadeo, A proposal for off-grid photovoltaic systems with non-controllable loads using fuzzy logic, Energy Conver. Manag. 78 (2014) 835-842.

[13] Edward Barbour, Marta C. González, Projecting battery adoption in the prosumer era, Appl. Energy 215 (2018) 356-370.

[14] Robert L. Fares, Michael E. Webber, The impacts of storing solar energy in the home to reduce reliance on the utility, Nature Energy 2 (2) (2017) 17001.

[15] Emil Nyholm, Joel Goop, Mikael Odenberger, Filip Johnsson, Solar photovoltaic-battery systems in Swedish households-Self-consumption and self-sufficiency, Appl Energy 183 (2016) 148-159.

[16] Reza Hemmati, Hedayat Saboori, Stochastic optimal battery storage sizing and scheduling in home energy management systems equipped with solar photovoltaic panels, Energy Build 152 (2017) 290-300.

[17] Johannes Weniger, Tjarko Tjaden, Volker Quaschning, Sizing of residential PV battery systems, Energy Procedia 46 (2014) 78-87.

[18] Alejandro Pena-Bello, Meinrad Burer, Martin K. Patel, David Parra, Optimizing PV and grid charging in combined applications to improve the profitability of residential batteries, J. Energy Storage 13 (2017) 58-72.
[19] Valentin Bertsch, Jutta Geldermann, Tobias Lühn, What drives the profitability of household PV investments, self-consumption and self-sufficiency? Appl. Energy 204 (2017) 1-15.

[20] Sylvain Quoilin, Konstantinos Kavvadias, Arnaud Mercier, Irene Pappone, Andreas Zucker, Quantifying self-consumption linked to solar home battery systems: statistical analysis and economic assessment, Appl. Energy 182 (2016) 58-67.

[21] Rasmus Luthander, Joakim Widén, Daniel Nilsson, Jenny Palm, Photovoltaic self-consumption in buildings: a review, Appl. Energy 142 (2015) 80-94.

[22] Christos D. Korkas, Simone Baldi, Iakovos Michailidis, Elias B. Kosmatopoulos, Occupancy-based demand response and thermal comfort optimization in microgrids with renewable energy sources and energy storage, Appl. Energy 163 (2016) 93-104.

[23] Andreas D. Georgakarakos, Martin Mayfield, Elizabeth Abigail Hathway, Battery Storage Systems in Smart Grid Optimised Buildings, Energy Procedia 151 (2018) 23-30.

[24] Jan Martin Zepter, Alexandra Lüth, Pedro Crespo del Granado, Ruud Egging, Prosumer integration in wholesale electricity markets: Synergies of peerto-peer trade and residential storage, Energy Build. 184 (2019) 163-176.

[25] Edward Barbour, David Parra, Zeyad Awwad, Marta C. González, Community energy storage: a smart choice for the smart grid? Appl. Energy 212 (2018) 489-497.

[26] David Parra, Mark Gillott, Stuart A. Norman, Gavin S. Walker, Optimum community energy storage system for PV energy time-shift, Appl. Energy 137 (2015) 576-587.

[27] David Parra, Maciej Swierczynski, Daniel I. Stroe, Stuart A. Norman, Andreas Abdon, Jörg Worlitschek, Travis O'Doherty, et al., An interdisciplinary review of energy storage for communities: challenges and perspectives, Renew. Susta. Energy Rev. 79 (2017) 730-749.

[28] Cody A. Hill, Matthew Clayton Such, Dongmei Chen, Juan Gonzalez, W. Mack Grady, Battery energy storage for enabling integration of distributed solar power generation, IEEE Trans. Smart Grid 3 (2) (2012) 850-857.

[29] Department of Energy and Climate Change. "Variation in Tariff Types and Energy Bills.” UK Government. Available at: https://assets.publishing.service. gov.uk/government/uploads/system/uploads/attachment_data/file/416052/ Variation_in_tariff_types_and_energy_bills.pdf (Accessed 20 January 2019).

[30] Oxford City Council, Reaction to Indices of Deprivation Figures, Oxford City Council, 2015 30th SeptemberAvailable at: https://www.oxford.gov.uk/news/ article/36/reaction_to_indices_of_deprivation_figures.

[31] Ofgem. "Typical Domestic Consumption Values." Ofgem. Available at: https://www.ofgem.gov.uk/gas/retail-market/monitoring-data-and-statistics/ typical-domestic-consumption-values (Accessed 20 January 2019).

[32] Department for Business, Energy \& Industrial Strategy. "Digest of UK Energy Statistics (DUKES) 2015." Available at: https://assets.publishing.service. gov.uk/government/uploads/system/uploads/attachment_data/file/450302/ DUKES_2015.pdf (Accessed 20 January 2019).

[33] Runming Yao, Koen Steemers, A method of formulating energy load profile for domestic buildings in the UK, Energy Build. 37 (6) (2005) 663-671.

[34] Jean-Paul Zimmermann, Matt Evans, Jonathan Griggs, Nicola King, Les Harding, Penelope Roberts, Chris Evans, Household Electricity Survey: A study of domestic electrical product usage, Intertek Test. Certif. Ltd (2012). 